\title{
O Ensino da “Extensão Rural” nos Cursos Superiores de Medicina Veterinária no Brasil
}

\section{The "Rural Extension" Teaching in Undergraduate Courses of Medicine Veterinary in Brazil}

\author{
Teresa Cristina ALVES ${ }^{1}$; Augusto Hauber GAMEIRO² \\ ${ }^{1}$ Faculdade de Zootecnia e Engenharia de Alimentos da Universidade de São Paulo, Pirassununga - SP, Brasil \\ ${ }^{2}$ Faculdade de Medicina Veterinária e Zootecnia da Universidade de São Paulo, Pirassununga - SP, Brasil
}

\begin{abstract}
Resumo
Esta pesquisa investigou como os Cursos Superiores de Medicina Veterinária no Brasil (CSMV) estão oferecendo conhecimentos relacionados à "Extensão Rural”. Foram aplicados questionários aos 149 cursos de Medicina Veterinária em funcionamento. Deste universo, obteve-se uma amostra de 57 entrevistados que responderam à pesquisa (38,3\%). Em que pesem as mudanças curriculares após o Parecer 105/2002, a disciplina ainda é oferecida na maioria (97\%) dos cursos, evidenciando o reconhecimento de sua importância na formação dos alunos de graduação. Três aspectos observados merecem reflexão: a heterogeneidade na carga horária da disciplina, variando de 30 a 90 horas/semestre; certa heterogeneidade da inserção (semestre/período) na grade, podendo constar desde o segundo até o último período; e a ampla gama de temas que constam nos programas. Sugere-se que os programas da disciplina de Extensão Rural, a serem oferecidos nos CSMV, procurem inserir três pontos que se entende serem importantes, mas nem sempre abordados: i) a "extensão rural" com seus múltiplos enfoques (serviço público para o desenvolvimento holístico das famílias rurais, assistência técnica propriamente dita, difusão de tecnologia, prática pedagógica, processo de comunicação etc.); ii) temas relacionados diretamente à atuação do médico veterinário (tais como a relação da extensão com a sanidade animal e humana, a defesa agropecuária etc.); e iii) temas emergentes relacionados a áreas multidisciplinares, especialmente a sustentabilidade, o meio ambiente e o bem-estar animal.
\end{abstract}

Palavras-chave: Extensão rural. Difusão de tecnologia. Ensino. Grade curricular.

\begin{abstract}
This research investigates how the Undergraduate Courses of Medicine Veterinary currently provide knowledge regarding "Rural Extension". It was applied questionnaires to the 149 courses in activity, out of which 57 answered the survey $(38.3 \%)$. Despite the curricular changes proposed by the government in 2002, the discipline is still offered in the majority of the schools (97\%), showing the recognition of its importance in the undergraduate student education. Three central aspects needs attention: the heterogeneity regarding the hours of the discipline, ranging from 30 to 90 hours per semester; a relative heterogeneity where the discipline is inserted in the curriculum, ranging from the second to the last semester; and the wide range of issues presented in the discipline's programs. It's suggested that the programs should try to include three sets of knowledge that are considered important to professionals of the future, and that appeared with little relevance in current programs: i) an extension with its multiple focus; ii) issues directly related to the veterinary actuation; and iii) emerging issues related to multidisciplinary areas, specially sustainability, the human-animal relation and the animal welfare.
\end{abstract}

Keywords: Rural extension. Technology diffusion. Teaching. Curriculum.

\section{Introdução}

A atividade de extensão rural é praticada há muitos séculos, existindo relatos de que o Imperador Romano Adriano, ao visitar o Egito, encontrou instrutores do faraó ensinando os agricultores das margens do Rio Nilo a plantar trigo irrigado ${ }^{1}$. Mas foi apenas no século XX que está prática ganhou status de ciência ou disciplina, estando fortemente ligada ao rápido desenvolvimento tecnológico da agricultura e da pecuária. Tal desenvolvimento foi denominando, por alguns cien- tistas sociais, de "capitalização da agricultura", como uma alusão ao uso intensivo de insumos (capital) na produção agropecuária ${ }^{2,3}$. As duas guerras mundiais foram determinantes neste contexto, pois aceleraram

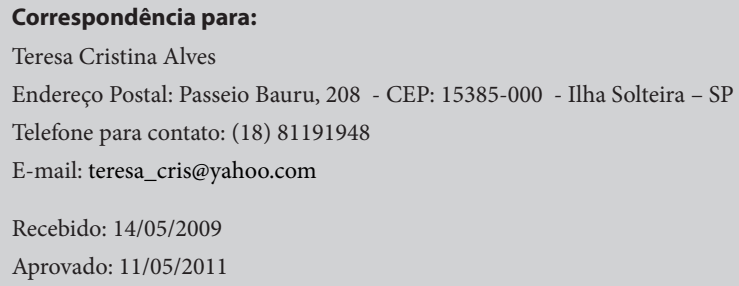


o desenvolvimento tecnológico nas áreas da química (defensivos), da mecânica (máquinas e irrigação) e da genética (melhoramento animal e vegetal). Para que toda essa tecnologia fosse transferida aos produtores rurais, surgiu oficialmente, em especial nos Estados Unidos, a atividade da extensão rural ${ }^{4}$.

Todavia, no Brasil, o uso intensivo de insumos e de novas tecnologias no campo gerou consequências negativas do ponto de vista social, como o êxodo rural e a concentração da renda ${ }^{2,5}$, e ambiental ${ }^{2,6}$. Dessa forma, correntes críticas ao modelo extensionista original surgiram com força, especialmente nos países latino-americanos nas décadas de 70 e 80 . O educador Paulo Freire é considerado o expoente nesse sentido, sendo a sua obra "Extensão ou Comunicação?"7 peça chave neste contexto ${ }^{8}$. A valorização do ser humano e seu desenvolvimento é a principal bandeira dessa linha de difusão. A "comunicação" (bidirecional) e não a "extensão" (unidirecional) propriamente dita seria o método recomendado para técnicos interagirem com as populações rurais e a elas passarem novos conhecimentos. Para Frei$\mathrm{re}^{7}$, o extensionista deveria ser um educador, contribuindo para a construção do saber juntamente com o produtor (denominado por ele, na época, de camponês), por meio da problematização do mundo; o homem do campo deveria ser sujeito do processo e não objeto. A construção aconteceria por meio de uma troca de experiências e não da simples transmissão do saber tecnicamente concebido ${ }^{7}$.

Atualmente, a atividade de difusão tecnológica, ou mais genericamente, de simplesmente levar conhecimento ao campo transita entre dois extremos que acabaram sendo assim rotulados: i) "assistência técnica", visando objetivamente à resolução de problemas técnicos e a transferência de tecnologia com vistas ao aumento da produtividade agropecuária; e ii) "extensão rural" propriamente dita, que, além do aspecto produtivista, apresenta uma visão holística que transcende os sistemas produtivos e preocupa-se com a melhoria de vida das pessoas que vivem no campo, sob suas mais diversas dimensões?.

Este artigo apresenta o objetivo de analisar como os Cursos Superiores de Medicina Veterinária no Brasil doravante apenas "CSMV" - estão oferecendo conhecimentos de extensão rural aos seus alunos. Dentre as questões de interesse constam: i) se há disciplina específica para o tema ou se o mesmo vem sendo abordado em outras matérias; ii) a formação dos professores responsáveis pelo conteúdo; iii) a carga horária; iv) o período ou semestre no qual é oferecida; e v) os tópicos que a compõem. Esta pesquisa surge em um período relevante na história do país, em que se reconhece a importância de uma atividade de difusão de tecnologia efetivamente holística, preocupada com o social e o meio ambiente, mas também engajada em um processo de crescimento econômico com constante aumento da produtividade agropecuária. A própria política do governo federal, intitulada "Política Nacional de Assistência Técnica e Extensão Rural” (PNATER), talvez seja a principal concretização desta tendência ${ }^{10}$. Paralelamente, as grades curriculares dos CSMV vêm claramente procurando ajustar-se a esse contexto ${ }^{11}$. A mudança na diretriz curricular em 2002 é uma evidência nesse sentido ${ }^{12}$.

\section{Material e Método}

Esta pesquisa pode ser classificada, quanto aos objetivos, como exploratória, pois procurou uma primeira aproximação com o tema, dado que a informação almejada não se encontrava sistematizada em fonte específica e organizada ${ }^{13}$. Foi elaborado um questionário estruturado não disfarçado ${ }^{14}$ que foi aplicado aos professores dos CSMV responsáveis pela disciplina de Extensão Rural ou equivalente. Entende-se por "equivalente" aquela que apresente o termo "extensão" em seu nome e que contenha em seu conteúdo, temas que sejam relacionados à difusão de tecnologia no meio agropecuário. Em alguns casos, na ausência desse professor específico, o respondente foi o coordenador do curso. 
Foram listados todos os cursos superiores de Medicina Veterinária do Brasil em funcionamento no mês de agosto de 2008. Tal informação foi obtida por meio do Guia do Estudante ${ }^{15}$ da Editora Abril. No total identificaram-se 149 CSMV. Por meio de visitas aos websites das instituições procurou-se identificar o professor responsável pela disciplina de extensão rural ou equivalente. Quando não encontrada esta informação, as instituições foram contatadas por meio de ligação telefônica direcionada ao diretor ou coordenador do curso. A totalidade dos CSMV identificados foi contatada para responder a pesquisa. O contato ocorreu por conversa telefônica, e-mail ou carta, conforme a disponibilidade do entrevistado.

Antes da aplicação definitiva do questionário, o mesmo foi testado em uma amostra de cinco entrevistados, para verificar a consistência e adequação do mesmo ${ }^{16,17}$. Juntamente com o questionário foi enviada uma carta assinada pelos autores no qual era explicado o objetivo da pesquisa. O questionário era composto por seis perguntas, além de solicitar o envio do programa e da bibliografia da disciplina de Extensão Rural ou equivalente. As perguntas que compunham o questionário eram: 1) Quando (ano) o curso de Medicina Veterinária foi iniciado na faculdade? 2) Quando (ano) a disciplina de "Extensão Rural" (ou equivalente) foi incluída na grade do curso? (Solicitava-se o favor de mencionar o nome da disciplina equivalente em sendo o caso); 3) Qual a formação acadêmica (graduação e pós-graduação em sendo o caso) do atual professor da referida disciplina no curso de Medicina Veterinária? 4) Qual o objetivo da disciplina no curso de Medicina Veterinária? 5) Em qual período a disciplina de "Extensão Rural" ou equivalente é ministrada no curso de Medicina Veterinária? 6) Qual é a carga horária da disciplina de "Extensão Rural" (ou equivalente) para o curso de Medicina Veterinária?

A partir das informações obtidas por meio dos questionários, pode-se avaliar: i) a evolução históri- ca do surgimento dos CSMV no Brasil, o nome das disciplinas equivalentes e o número de CSMV que as oferecem; ii) a formação, em termos de graduação, do professor responsável; iii) a carga horária das disciplinas; e iv) a distribuição de frequência da sua inserção na grade curricular. Para o estudo comparativo da carga horária das disciplinas específicas de Extensão Rural em relação àquelas equivalentes, utilizou-se o teste F com 95\% de significância para testar a hipótese de igualdade entre as variâncias dos dois grupos. Na sequência foi então utilizado o teste t com 95\% para se verificar a hipótese de diferença entre as médias. Em função do resultado prévio do teste $\mathrm{F}, \mathrm{o}$ teste $\mathrm{t}$ considerou amostras com variâncias iguais ou diferentes. Esses testes estão descritos em Hoffmann ${ }^{18}$. Objetivou-se, com esta análise estatística, melhor conhecer a dedicação dos CSMV ao estudo do tema, independentemente da denominação específica da matéria.

Realizou-se, também, a análise qualitativa dos conteúdos programáticos das disciplinas, com o objetivo de sistematizar os tópicos abordados e comparar as instituições quanto a esse aspecto.

\section{Resultados e Discussão}

No Brasil a extensão rural foi oficialmente introduzida a partir de 1948, com apoio econômico de organizações publicas e privadas dos Estados Unidos, como parte dos programas de ajuda ao desenvolvimento do Terceiro Mundo. Assim, os modelos, objetivos e prática da extensão rural brasileira não nasceram de uma demanda local e, ademais, também não se desenvolveram apoiados em uma base teórica que corresponde à realidade do meio rural e do desenvolvimento agrário brasileiro ${ }^{19,20}$.

As Escolas Superiores de Lavras e de Viçosa foram precursoras desse modelo. Em Lavras, 1921, iniciaram-se trabalhos de difusão técnico-científicos com a publicação da revista "O Agricultor", com a inten- 
ção de "difundir e educar os agropecuaristas brasileiros", assim como promover o desenvolvimento rural do país. A Escola Superior de Agricultura de Viçosa, inaugurada em 1926, promoveu a "Semana do Fazendeiro" pela primeira vez no ano de 1929, dando início às atividades extensionistas ${ }^{21,22}$.

Até o ano de 1960 tinham sido criados 20 cursos de Agronomia e Veterinária no Brasil. As escolas funcionaram com cursos ora de Veterinária, ora de Agronomia, ora com ambos. Muitas delas hoje estão extintas. A partir de 1961 ocorre uma expansão de escolas superiores e foram criados outros cursos na Área de Ciências Agrárias como Zootecnia, Engenharia Agrícola e Engenharia Florestal ${ }^{23}$.
No ano de 1962 o Conselho Federal de Educação aprovou o currículo mínimo do curso de Medicina Veterinária, que foi estruturado a partir de análise dos currículos completos recebidos de oito faculdades e escolas de Veterinária do país. A partir de 1977 a Comissão de Especialistas do Ensino de Ciências Agrárias (CECA) começou a estudar a reformulação do currículo mínimo e em abril de 1984 foi instituído um novo currículo mínimo para o curso de Medicina Veterinária. Nesse novo currículo mínimo foi introduzida entre outras a disciplina de Extensão Rural (Quadro 1).

No ano de 2002 foi aprovada a atual diretriz curricular para o curso de Medicina Veterinária por meio do parecer CNE/CNS 105/2002, do Conselho Nacio-

(continua)

\begin{tabular}{|c|c|c|}
\hline PARECER No 256/1962 & PARECER No $1 / 1984$ & PARECER No $105 / 2002$ \\
\hline \multicolumn{3}{|c|}{ MATÉRIAS DE FORMAÇÃO BÁSICA } \\
\hline Duração mínima: 4 anos letivos & Duração mínima 3.600 horas & Duração mínima 4.000 horas \\
\hline 1. Bioquímica & $\begin{array}{l}\text { 1. Química: Química Orgânica. Bioquímica. } \\
\text { Fisicoquimica e Elementos de Química } \\
\text { Analítica. }\end{array}$ & \multirow{3}{*}{$\begin{array}{l}\text { 1. Ciências Biológicas e da Saúde - incluem- } \\
\text { se os conteúdos (teóricos e práticos) de } \\
\text { base moleculares e celulares dos processos } \\
\text { normais e alterados, da estrutura e função } \\
\text { dos tecidos, órgãos, sistemas e aparelhos, } \\
\text { bem como processos bioquímicos, biofísicos, } \\
\text { microbiológicos, imunológicos, genética } \\
\text { molecular e bioinformática em todo } \\
\text { desenvolvimento do processo saúde-doença, } \\
\text { inerentes à Medicina Veterinária. }\end{array}$} \\
\hline $\begin{array}{l}\text { 2. Anatomia. Histologia e Embriologia dos } \\
\text { animais domésticos }\end{array}$ & $\begin{array}{l}\text { 2. Morfologia dos Animais Domésticos: } \\
\text { Citologia. Histologia. Embriologia e Anatomia } \\
\text { dos animais Domésticos. }\end{array}$ & \\
\hline 3. Fisiologia, Biologia, Farmacologia & $\begin{array}{l}\text { 3. Fisiologia dos Animais Domésticos: Fisiologia, } \\
\text { Farmacologia e Biofísica. }\end{array}$ & \\
\hline 4. Genética Animal & $\begin{array}{l}\text { 4. Genética Animal: Genética Mendeliana. } \\
\text { Genética Molecular. Citogenética e Evolução. } \\
\text { Genética de Microrganismo. Biotecnologia. }\end{array}$ & \\
\hline 5. Microbiologia & $\begin{array}{l}\text { 5. Microbiologia: Bacteriologia. Virologia. } \\
\text { Micologia e Requetiologia. }\end{array}$ & \\
\hline 6. Imunologia & $\begin{array}{l}\text { 6. Imunologia: Imunologia Geral. } \\
\text { Imunoquimica. Imunopatologia. }\end{array}$ & \\
\hline 7. Parasitologia & $\begin{array}{l}\text { 7. Parasitologia: Protozoologia. Helmintologia e } \\
\text { Entomologia Veterinária. }\end{array}$ & \\
\hline 8. Bioestatística & $\begin{array}{l}\text { 8. Matemática e estatística: Elementos de } \\
\text { Matemática. Estatística Descritiva. Estatística } \\
\text { Experimental. Estatística Inferencial } \\
\text { e Bioestatística. Conceitos Básicos de } \\
\text { Computação. }\end{array}$ & \\
\hline \multicolumn{3}{|c|}{ MATÉRIAS DE FORMAÇÃO GERAL } \\
\hline $\begin{array}{l}\text { 1. Ciências Humanas e Sociais (não } \\
\text { constava no currículo mínimo) }\end{array}$ & $\begin{array}{l}\text { 1. Ciências Humanas e Sociais: Fisiologia da } \\
\text { Ciência e Elementos de sociologia. Antropologia. } \\
\text { Sociologia Rural. Deontologia. }\end{array}$ & \multirow{2}{*}{$\begin{array}{l}\text { 1. Ciências Humanas e Sociais - incluem-se } \\
\text { os conteúdos referentes às diversas dimensões } \\
\text { da relação indivíduo/sociedade, contribuindo } \\
\text { para a compreensão dos determinantes sociais, } \\
\text { culturais, comportamentais, psicológicos, } \\
\text { ecológicos, éticos e legais e conteúdos } \\
\text { envolvendo a comunicação, a informática, a } \\
\text { economia e gestão administrativa em nível } \\
\text { individual e coletivo }\end{array}$} \\
\hline $\begin{array}{l}\text { 2. Ciências do Ambiente (não constava no } \\
\text { currículo mínimo) }\end{array}$ & $\begin{array}{l}\text { 2. Ciências do Ambiente: Biosfera e seu } \\
\text { Equilíbrio. Efeitos da Tecnologia sobre o } \\
\text { Equilíbrio Ecológico. Preservação dos recursos } \\
\text { Naturais. Manejo de Fauna Silvestre. Poluição. }\end{array}$ & \\
\hline
\end{tabular}

Quadro 1 - Comparação entre o currículo mínimo de Medicina Veterinária aprovado em 1962 (Parecer nº 256/1962), aprovado em 1984 (Parecer no 1/1984) e os conteúdos essenciais para o curso de Medicina Veterinária segundo as novas diretrizes curriculares (Parecer n 105/2002): matérias de formação básica 
(continuação)

\begin{tabular}{|c|c|c|}
\hline \multicolumn{3}{|c|}{ MATÉRIAS DE FORMAÇÃO PROFISSIONAL } \\
\hline 1. Anatomia Patológica & $\begin{array}{l}\text { 1. Anatomia Patológica dos Animais } \\
\text { Domésticos: Geral e Especial. Técnicas de } \\
\text { Necropsia. Medicina Veterinária Legal. }\end{array}$ & \multirow{2}{*}{$\begin{array}{l}\text { 1. Ciências da Medicina Veterinária- incluem- } \\
\text { se os conteúdos teóricos e práticos relacionados } \\
\text { com saúde-doença, produção animal e ambiente, } \\
\text { com ênfase nas áreas de Saúde Animal, Clínica } \\
\text { e Cirurgia veterinárias, Medicina Veterinária } \\
\text { Preventiva, Saúde Pública, Zootecnia, Produção } \\
\text { Animal e Inspeção e Tecnologia de Produtos } \\
\text { de origem Animal, contemplando os conteúdos } \\
\text { teóricos e práticos a seguir: }\end{array}$} \\
\hline $\begin{array}{l}\text { 2. Clinica Medica dos Animais Domésticos. } \\
\text { Agrostologia e Plantas Tóxicas. Patologia } \\
\text { Clinica }\end{array}$ & $\begin{array}{l}\text { 2. Clinica Médica dos Animais Domésticos: } \\
\text { Semiologia. Patologia e Clinica Medica. } \\
\text { Toxicologia e Plantas Tóxicas. Terapêutica e } \\
\text { Radiologia. }\end{array}$ & \\
\hline $\begin{array}{l}\text { 3. Clínica Cirúrgica dos Animais } \\
\text { Domésticos, Incluindo Técnica Cirúrgica e } \\
\text { Obstetrícia }\end{array}$ & $\begin{array}{l}\text { 3. Cirurgia Médica dos Animais Domésticos: } \\
\text { Patologia e Clinica Cirúrgica. Técnicas } \\
\text { Cirúrgicas. Anestesiologia. }\end{array}$ & \multirow{2}{*}{$\begin{array}{l}\text { 2. Clínica Veterinária - incorporando } \\
\text { conhecimentos de clínica, cirurgia e } \\
\text { fisiopatologia da reprodução com ênfase nos } \\
\text { aspectos semiológicos e laboratoriais, visando à } \\
\text { determinação da etiopatogenia, do diagnóstico } \\
\text { e dos tratamentos médico ou cirúrgico das } \\
\text { enfermidades de diferentes naturezas. }\end{array}$} \\
\hline 4. Fisiopatologia da Reprodução & $\begin{array}{l}\text { 4. Fisiologia e Fisiopatologia da Reprodução } \\
\text { dos Animais Domésticos: Fisiopatologia e } \\
\text { endocrinologia. Ginecologia e Obstetrícia. } \\
\text { Andrologia. Inseminação Artificial e Tecnologia } \\
\text { de Sêmen. }\end{array}$ & \\
\hline $\begin{array}{l}\text { 5. Higiene e Saúde Pública. Doenças } \\
\text { Infecciosas e Parasitárias }\end{array}$ & $\begin{array}{l}\text { 5. Medicina Veterinária Preventiva e Saúde } \\
\text { Publica: Doenças Infectocontagiosas e } \\
\text { Parasitárias. Zoonoses. Ornitopatologia. } \\
\text { Epidemiologia e Saneamento. Administração } \\
\text { e Educação Sanitária. Planejamento de Saúde } \\
\text { Animal e Saúde Pública. }\end{array}$ & $\begin{array}{l}\text { 3. Medicina Veterinária Preventiva e Saúde } \\
\text { Pública - reunindo conteúdos essenciais às } \\
\text { atividades destinadas ao planejamento em saúde, } \\
\text { a epidemiologia, controle e erradicação das } \\
\text { enfermidades infecto-contagiosas, parasitárias } \\
\text { e zoonoses, saneamento ambiental, produção e } \\
\text { controle de produtos biológicos. }\end{array}$ \\
\hline 6. Tecnologia de Produtos Animais & $\begin{array}{l}\text { 6. Tecnologia de Produtos de Origem Animal: } \\
\text { Processamento, Classificação de Produtos de } \\
\text { Origem Animal. }\end{array}$ & $\begin{array}{l}\text { 4. Inspeção e Tecnologia dos Produtos de } \\
\text { Origem Animal - incluindo classificação, } \\
\text { processamento, padronização, conservação e } \\
\text { inspeção higiênica e sanitária dos produtos de } \\
\text { origem animal e dos seus derivados. }\end{array}$ \\
\hline $\begin{array}{l}\text { 7. Inspeção: (não constava no currículo } \\
\text { mínimo) }\end{array}$ & $\begin{array}{l}\text { 7. Higiene e Inspeção de Produtos de Origem } \\
\text { Animal: Higiene e Inspeção Industrial e } \\
\text { Sanitária. Higiene e Inspeção Sanitária de } \\
\text { Produtos de Origem animal. Inspeção Industrial. } \\
\text { Legislação. }\end{array}$ & \\
\hline $\begin{array}{l}\text { 8. Zootecnia. Melhoramento dos Animais. } \\
\text { Nutrição Animal }\end{array}$ & $\begin{array}{l}\text { 8. Zootecnia: Criação e Exploração Econômica } \\
\text { de Animais. Instalações. Nutrição Animal. } \\
\text { Alimentos. Forragicultura. Bromatologia. } \\
\text { Exterior e Julgamento dos Animais. } \\
\text { Melhoramento Animal. Bioclimatologia. }\end{array}$ & $\begin{array}{l}\text { 5. Zootecnia e Produção Animal - envolvendo } \\
\text { sistemas de criação, manejo, nutrição, } \\
\text { biotécnicas da reprodução, exploração } \\
\text { econômica e ecologicamente sustentável, } \\
\text { incluindo agronegócios }\end{array}$ \\
\hline $\begin{array}{l}\text { 9. Economia e Administração Rural; (não } \\
\text { constava no currículo mínimo) }\end{array}$ & $\begin{array}{l}\text { 9. Economia e Administração Rural: Teoria } \\
\text { Econômica. Micro e Macroeconomia } \\
\text { Aplicada. Cooperativismo e Crédito Rural. } \\
\text { Comercialização Administração e Planejamento. } \\
\text { Legislação e Política Agrária. }\end{array}$ & \\
\hline $\begin{array}{l}\text { 10. Extensão Rural: (não constava no } \\
\text { currículo mínimo) }\end{array}$ & $\begin{array}{l}\text { 10. Extensão Rural: Fundamentos da Extensão. } \\
\text { Comunicação. Difusão de Inovações. } \\
\text { Metodologia de Extensão. Desenvolvimento de } \\
\text { Comunidades. }\end{array}$ & \\
\hline
\end{tabular}

Quadro 1 - Comparação entre o currículo mínimo de Medicina Veterinária aprovado em 1962 (Parecer n 256/1962), aprovado em 1984 (Parecer no 1/1984) e os conteúdos essenciais para o curso de Medicina Veterinária segundo as novas diretrizes curriculares (Parecer n 105/2002): matérias de formação básica

nal de Educação/Câmara de Educação Superior ${ }^{12}$, e instituída pela Resolução CNE/CNS 1/200324. Esta tinha dentre os seus objetivos, o de conferir maior autonomia às Instituições de Ensino Superior (IES) na definição dos currículos de seus cursos. Isso ocorreria a partir da explicitação das competências e as habilidades que se desejaria desenvolver, por meio da organização de um modelo pedagógico capaz de adaptarse à dinâmica das demandas da sociedade, em que a graduação passava a constituir uma etapa de formação inicial no processo contínuo de educação permanente $^{25}$. Esse fato foi relevante, pois abriu espaço para a diversidade na formação do profissional dentro das diferentes faculdades de Medicina Veterinária.

Dos 149 CSMV identificados nesta pesquisa, de apenas 57 deles houve resposta por parte dos entrevistados, totalizando uma amostra final de $38,3 \%$ do universo, o que pode ser considerado razoável por alguns autores, 
como Gil ${ }^{16}$ e Goode e Hatt ${ }^{17}$. Ainda assim, por contemplar apenas parte das instituições existentes, os resultados devem ser considerados com a devida ressalva. Ademais, nem todos os 57 entrevistados responderam a todas as questões, de modo que, durante a apresentação dos resultados, o número total de respondentes para as respectivas questões foi destacado.

$\mathrm{O}$ primeiro resultado disse respeito à evolução do surgimento dos cursos de Medicina Veterinária da amostra. Esta informação é apresentada na tabela 1.

Observa-se na tabela 1 que a maior parte dos cursos de Medicina Veterinária é bastante recente, sendo que $72 \%$ dos amostrados surgiram a partir da década de 90 .

Em relação à existência da disciplina de "Extensão Rural” ou equivalente, nas grades curriculares dos CSMV, observou-se que praticamente a totalidade das instituições a oferecem, ainda que com alguma denominação distinta ou conjuntamente com outras maté- rias (como a "Sociologia", por exemplo). Os resultados agregados são apresentados na tabela 2 .

Apenas duas instituições, dentre as 57 respondentes, declararam não oferecer a disciplina de "Extensão Rural" ou equivalente em seu curso. Por outro lado, 97\% das escolas oferecem-na, ainda que com alguma denominação distinta ou associada à outra. Interessante notar que quase $74 \%$ dos cursos oferecem-na exatamente com a denominação "Extensão Rural".

A análise do oferecimento da disciplina indica que as escolas estão alinhadas com o Parecer n. 1 de 1984, que sugere a "Extensão Rural" como específica $\left(10^{a}\right.$ matéria, conforme ilustrado na Quadro 1), inclusive desvinculada de outras da área de humanas, como Economia, Sociologia, Administração etc. Já o Parecer n. 105 de 2002 - atualmente em vigência - apresenta uma sugestão mais agregada, com apenas cinco grandes áreas, dentre as quais, as disciplinas de humanas estariam contidas

Tabela 1 - Evolução do surgimento dos cursos de Medicina Veterinária no Brasil que compõem a amostra

\begin{tabular}{ccc}
\hline Período & Número de cursos & Participação (\%) \\
\hline 1910 a 1960 & 1 & 1,9 \\
1961 a 1970 & 4 & 7,4 \\
1971 a 1980 & 8 & 14,8 \\
1981 a 1990 & 2 & 3,7 \\
1991 a 2000 & 20 & 37,0 \\
2001 a 2008 & 19 & 35,2 \\
\hline Total de respondentes & $\mathbf{5 4}$ & $\mathbf{1 0 0 , 0}$ \\
\hline
\end{tabular}

Tabela 2 - Nome das disciplinas equivalentes e número de cursos de Medicina Veterinária que as oferecem

\begin{tabular}{|c|c|c|}
\hline Nome da disciplina & Número de cursos & Participação (\%) \\
\hline Extensão Rural & 42 & 73,7 \\
\hline Outros nomes semelhantes ${ }^{*}$ & 7 & 12,3 \\
\hline Sociologia e Extensão Rural & 4 & 7,0 \\
\hline Sociologia e Extensão & 2 & 3,5 \\
\hline Sem disciplina equivalente & 2 & 3,5 \\
\hline Total de respondentes & 57 & 100,0 \\
\hline
\end{tabular}


na quinta e última área, denominada de "Zootecnia e Produção Animal". Nesse sentido, é importante mencionar que 10,5\% das escolas já oferecem a "Extensão" conjuntamente com a de "Sociologia", provavelmente como consequência dessa agregação proposta recentemente. Tal agregação pode ser positiva especialmente para possibilitar aos alunos a compreensão menos fragmentada dos saberes relacionados.

A formação do professor responsável pela disciplina de "Extensão Rural" ou equivalente pode ser observada na tabela 3.

Observa-se uma heterogeneidade significativa na formação - em nível de graduação - do docente, sendo que foram identificadas nove profissões diferentes.
Apesar dessa diversidade, há um domínio de engenheiros agrônomos (em 32,7\% dos cursos) e de médicos veterinários (em $25 \%$ dos cursos).

A pesquisa procurou explorar a carga horária dedicada ao ensino da Extensão Rural ou equivalente. Tratase de uma questão usualmente discutida em revisões curriculares. Para se analisar a carga, separaram-se os cursos em dois grupos. Em um grupo foram considerados os cursos que têm a disciplina exatamente com a denominação de "Extensão Rural"; e em um segundo grupo os cursos que a oferecem conjuntamente com outras, ou que oferecem matérias semelhantes, mas sem a denominação específica de "Extensão Rural". Os resultados são apresentados na tabela 4 .

Tabela 3 - Formação (graduação) do professor responsável pela disciplina de Extensão Rural ou equivalente

\begin{tabular}{lcc}
\hline \multicolumn{1}{c}{ Formação do professor } & Número de cursos & Participação (\%) \\
\hline Engenheiro Agrônomo & 17 & 32,7 \\
Médico Veterinário & 13 & 25,0 \\
Sem professor na ocasião & 7 & 13,5 \\
Zootecnista & 6 & 11,5 \\
Sociólogo & 3 & 5,8 \\
Economista & 2 & 3,8 \\
Pedagogo & 1 & 1,9 \\
Engenheiro Florestal & 1 & 1,9 \\
Bacharel em História & 1 & 1,9 \\
Assistente Social & 1 & 1,9 \\
\hline Total de respondentes & $\mathbf{5 2}$ & $\mathbf{1 0 0 , 0}$ \\
\hline
\end{tabular}

Tabela 4 - Carga horária das disciplinas (em hora-aula) dos cursos

\begin{tabular}{|c|c|c|}
\hline $\begin{array}{l}\text { Estatísticas da carga } \\
\text { horária }\end{array}$ & $\begin{array}{l}\text { Disciplinas com } \\
\text { denominação } \\
\text { "Extensão Rural" }\end{array}$ & $\begin{array}{l}\text { Disciplinas } \\
\text { equivalentes }^{\star}\end{array}$ \\
\hline Mínima & 30 & 30 \\
\hline Máxima & 72 & 90 \\
\hline Média & 48,1 & 51,8 \\
\hline Moda & 60 & 60 \\
\hline Mediana & 45 & 45 \\
\hline Variância & 121,8 & 327,2 \\
\hline
\end{tabular}


Um resultado interessante é o de que há certa variabilidade de carga horária - observada pelas variâncias na tabela 4 - entre os CSMV analisados. As disciplinas em questão apresentam, no mínimo, 30 horas-aula de carga e, no máximo, 72 horas (para as específicas) ou 90 horas (para as equivalentes ou agregadas). A carga horária mais comum (representada pela moda) para a disciplina é de 60 horas, independente de ser ou não específica de Extensão Rural.

Apesar da maior variabilidade aparente no grupo das disciplinas equivalentes, poder-se-ia imaginar que sua carga horária média pudesse ser superior à das exclusivas de extensão rural, uma vez que tratam de outros temas e mesmo de outras áreas de conhecimentos. $\mathrm{O}$ teste $\mathrm{F}$ aplicado às variâncias do primeiro grupo em comparação às do segundo, não permitiu a rejeição da hipótese de que são equivalentes (F calculado igual a 0,37 ; F crítico a 95\% igual a 0,46). Portanto, foi realizado o teste $t$ para amostras de variâncias iguais. O resultado deste último não permitiu a rejeição da hipótese de nulidade ( $\mathrm{t}$ calculado igual a 0,$81 ; \mathrm{t}$ crítico a $95 \%$ igual a 2,01 ), indicando que, estatisticamente, a média das cargas horárias das disciplinas específicas de Extensão Rural pode ser equivalente à daquelas que tratam a extensão de forma conjunta com outras ciências, especialmente a Sociologia. Portanto, conclui-se que apesar de diferença nas denominações, há equivalência em termos de participação quantitativa das mesmas nas grades.

Outra questão da pesquisa e que comumente acomete os responsáveis pela organização de uma grade curricular, está relacionada ao período (semestre) em que a disciplina de Extensão Rural ou equivalente é oferecida. Os resultados são apresentados na tabela 5 .

Há uma concentração do oferecimento da disciplina do meio para o final do curso (do $5^{\circ}$ para o $10^{\circ}$ semestre). Em $70 \%$ dos cursos, é oferecida a partir do $5^{\circ}$ semestre, com uma incidência mais expressiva no $9^{\circ}$ semestre (penúltimo). Os outros períodos mais recorrentes são o oitavo, o sétimo e o quinto. Calculou-se, ainda, a média (ao redor do $7^{\circ}$. semestre), a moda ( $9^{\circ}$. semestre) e a mediana ( $7^{\circ}$. semestre) em que a matéria ou sua equivalente é oferecida. O currículo mínimo instituído em 1984 inseria a "Extensão Rural" como uma matéria de formação profissional. Muito embora as diretrizes de 2002 não estabeleçam essa relação, é razoável considerar o conhecimento de extensão rural como profissionalizante, uma vez que se trata de uma área aplicada, fundamentando sua inclusão predominantemente nos últimos períodos dos CSMV.

Tabela 5 - Distribuição de frequência da localização da disciplina de Extensão Rural ou equivalente na grade curricular dos cursos (semestre)

\begin{tabular}{ccc}
\hline Semestre & Número de cursos & Participação (\%) \\
\hline $1^{\circ}$ & 0 & 0,0 \\
$2^{\circ}$ & 3 & 5,9 \\
$3^{\circ}$ & 2 & 3,9 \\
$4^{\circ}$ & 3 & 5,9 \\
$5^{\circ}$ & 7 & 13,7 \\
$6^{\circ}$ & 4 & 7,8 \\
$7^{\circ}$ & 7 & 13,7 \\
$8^{\circ}$ & 8 & 15,7 \\
$9^{\circ}$ & 16 & 31,4 \\
$10^{\circ}$ & 1 & 2,0 \\
\hline Total de respondentes & $\mathbf{5 1}$ & $\mathbf{1 0 0 , 0}$ \\
\hline
\end{tabular}


Finalmente, procedeu-se com uma análise do programa das disciplinas de Extensão Rural ou equivalente, de modo a se explorar os assuntos que vêm sendo tratados no contexto. Dessa forma, a análise foi feita a partir dos programas apresentados pelos CSMV. Houve o esforço de se sistematizar os assuntos, que apresentam uma natural sobreposição. A tipologia apresentada foi baseada nas próprias sistematizações constantes nos conteúdos programáticos. O resultado consta na tabela 6.

Como esperado, o principal tema dos programas foi "Extensão Rural", considerando seus aspectos históricos, seus conceitos, sua filosofia e seus modelos, sendo que quase $80 \%$ dos cursos o abordam explicitamente.
Todavia, observa-se uma grande diversidade de temas e que, de fato, apresentam alguma relação com a Extensão Rural, ou mesmo sobreposição e complementaridade com a mesma. Destaque, nesse sentido, para as temáticas "Modernização e desenvolvimento" e "Comunicação".

A Sociologia - que inclusive acaba dividindo o nome da disciplina com a Extensão Rural em 10,5\% dos cursos, como já abordado - consta em $27 \%$ dos programas. Mas as Ciências Sociais também aparecem indiretamente com temas centrais, tais como "Movimentos sociais e questões agrárias" e "Organizações e ações comunitárias"26.

Tabela 6 - Conteúdo das disciplinas de Extensão Rural ou equivalente nos cursos

\begin{tabular}{|c|c|c|}
\hline Tema & $\begin{array}{c}\text { Número de cursos } \\
\text { que contemplam o } \\
\text { tema }\end{array}$ & Participação (\%) \\
\hline $\begin{array}{l}\text { Extensão Rural (conceitos, história, } \\
\text { filosofia, modelos) }\end{array}$ & 41 & 78,8 \\
\hline Modernização e desenvolvimento & 30 & 57,7 \\
\hline Comunicação & 22 & 42,3 \\
\hline Movimentos sociais e questão agrária & 17 & 32,7 \\
\hline Difusão e transferência de tecnologia & 16 & 30,7 \\
\hline Organizações e ações comunitárias & 15 & 28,8 \\
\hline Sociologia & 14 & 26,9 \\
\hline Sustentabilidade e meio ambiente & 8 & 15,4 \\
\hline Políticas agrícolas & 8 & 15,4 \\
\hline $\begin{array}{l}\text { Papel do veterinário, sanidade animal, } \\
\text { política sanitária }\end{array}$ & 8 & 15,4 \\
\hline Agricultura familiar & 6 & 11,5 \\
\hline Agronegócio & 4 & 7,7 \\
\hline Marketing rural & 3 & 5,8 \\
\hline Teoria Econômica & 2 & 3,8 \\
\hline Comercialização & 2 & 3,8 \\
\hline Educação & 2 & 3,8 \\
\hline Bem estar animal & 1 & 1,9 \\
\hline Total de respondentes & 52 & 100,0 \\
\hline
\end{tabular}


Os temas eminentemente multidisciplinares ainda aparecem discretamente nos programas das disciplinas em análise: "Sustentabilidade e meio ambiente" ou "Papel do médico veterinário, sanidade animal e política sanitária" aparecem em 15\%; e "Bem estar animal", em $1,9 \%$, ou seja, em apenas um dos cursos respondentes.

Interessante destacar que o tema "Comunicação" apresentou uma ocorrência relativamente expressiva (58\% dos cursos). A "Educação" é tratada explicitamente em apenas 3,8\% dos cursos analisados, ou seja, consta em apenas dois dos 52 programas respondentes dentre os 57 amostrados.

\section{Conclusões}

A primeira conclusão é a de que, apesar das mudanças curriculares nas escolas de Medicina Veterinária ocorridas nos últimos anos, especialmente após o Parecer 105/2002, a disciplina de "Extensão Rural" continua sendo oferecida na maioria dos cursos, conforme preconizava o Parecer 1/1984, evidenciando o reconhecimento de sua importância na formação dos futuros médicos veterinários brasileiros. Apesar da ampla presença nas grades, concluem-se três aspectos que merecem reflexão: i) uma heterogeneidade de carga horária, variando de 30 a 90 horas/semestre; ii) certa heterogeneidade da inserção (semestre/período) na grade, podendo constar desde o segundo até o último (décimo) período, ainda que haja uma concentração maior na segunda metade do curso; e iii) uma ampla e variada gama de temas que constam nos programas oferecidos.

\section{Referências}

1. OLINGER, G. Métodos de extensão rural. Florianópolis: Epagri, 2006. 163 p.

2. GRAZIANO DA SILVA, J. A nova dinâmica da agricultura brasileira. 2. ed. Campinas: UNICAMP, 1998. 211 p.

3. FIGUEIREDO, N. M. S. Modernização, distribuição da renda e pobreza na agricultura brasileira: 1975, 1980 e 1985. 1996. 248 p. Tese (Doutorado) - Escola Superior de Agricultura "Luiz de Queiroz", Universidade de São Paulo, Piracicaba, 1996.
Esses três pontos estão, de alguma forma, correlacionados. Por ser uma disciplina da área de humanas, há alguma subjetividade envolvida na sua composição, dando ampla margem para as mais diferentes linhas e visões sobre os mais diferentes assuntos relacionados à atuação do futuro médico veterinário enquanto agente social, responsável pela difusão de tecnologias e pelo desenvolvimento da sociedade de uma forma geral. Ainda assim, os cursos procuram não perder o foco na "Extensão Rural" propriamente dita, seu histórico, sua filosofia e seus métodos. Essa vasta natureza permite uma carga horária elástica conforme observado.

Finalmente, sugere-se que os programas da disciplina de Extensão Rural ou equivalente - a serem oferecidos nos CSMV - procurem considerar três pontos que se entende serem importantes, mas nem sempre abordados: i) a "extensão rural" com seus múltiplos enfoques (serviço público para o desenvolvimento holístico das famílias rurais, assistência técnica propriamente dita, difusão de tecnologia, prática pedagógica, processo de comunicação etc.); ii) temas relacionados diretamente à atuação do médico veterinário (tais como a relação da extensão com a sanidade animal e humana, a defesa agropecuária etc.); e iii) temas emergentes relacionados a áreas multidisciplinares, especialmente a sustentabilidade, o meio ambiente e o bem-estar animal.

\section{Agradecimento}

Os autores agradecem às 57 instituições brasileiras de ensino superior em Medicina Veterinária que responderam o questionário que embasou esta pesquisa.

4. TOURINHO, M. M.; CRUZ, L. Sociologia da agricultura: um novo enfoque para a sociologia rural. Revista de Economia Rural, v. 24, n. 2, p. 251-266, 1986.

5. VEIGA, J. E. O Brasil rural ainda não encontrou seu eixo de desenvolvimento. Estudos Avançados, v. 15, n. 3, p. 101-119, 2001

6. LANA, R. P. Uso racional de recursos naturais não-renováveis: aspectos biológicos, econômicos e ambientais. Revista Brasileira de Zootecnia, v. 38, p. 330-340, 2009. Suplemento especial. 
7. FREIRE, P. Extensão ou comunicação? Trad. Rosisca Darcy de Oliveira. Rio de Janeiro: Paz e Terra, 1977. 93 p.

8. CALLOU, A. B. F.; SILVA PIRES, M. L. L.; LEITÃO, M. R. F. A.; SANTOS, M. S. T. O estado da arte do ensino da Extensão Rural no Brasil. Revista Extensão Rural, v. 15, n. 16, 2008. Disponível em: <http://w3.ufsm.br/extensaorural/art3ed16. pdf>. Acesso em: 6 maio 2011.

9. RIBEIRO, J. P. A saga da extensão rural em Minas Gerais. São Paulo: AnnaBlume, 2000. 270 p.

10.BRASÍLIA. Ministério do Desenvolvimento Agrário. Secretaria da Agricultura Familiar. Departamento de Assistência Técnica e Extensão Rural. Política Nacional de Assistência Técnica e Extensão Rural. Brasília, 2007. Disponível em: <http:// www.mda.gov.br/portal/saf/arquivos/download/Pnater. doc?version_id=2390213 $>$. Acesso em: 06 maio 2011 .

11.ARAUJO, R. T.; PETTAN, K. B. Resenha: a política nacional de assistência técnica e extensão rural (PNATER) e o novo perfil profissional do médico veterinário. Revista de Ciências Veterinárias, v. 5, n. 5, p. 96-98, 2007.

12.BRASIL. Ministério da Educação. Conselho Nacional de Educação. Parecer CNE/CES 105/2002. Diário Oficial da União, Brasília, 11 abr. de 2002. Sec. 1, p.14.

13.SANTOS, A. R. Metodologia científica: a construção do conhecimento. Rio de Janeiro: Lamparina, 2007. 192 p.

14.SAMARA, B. S.; BARROS, J. C. Pesquisa de marketing: conceitos e metodologias. 3. ed. São Paulo: Prentice Hall, 2002. $259 \mathrm{p}$.

15.GUIA DO ESTUDANTE. São Paulo: Editora Abril, 2008.

16. GIL, A. C. Como elaborar projetos de pesquisa. São Paulo: Atlas, 1987, 159 p.
17.GOODE, W. J.; HATT, P. K. Métodos em pesquisa social. Trad. C. M. Bori. 2. ed. São Paulo: Companhia Editora Nacional, 1968. $488 \mathrm{p}$

18. HOFFMANN, R. Estatística para economistas. 2. ed. São Paulo: Pioneira, 1991. 426 p.

19. CAPORAL, F. R. A extensão rural no Rio Grande do Sul: da tradição "Made in USA" ao paradigma agroecológico. Biblioteca Digital da EMATER/RS. 2001. Disponível em: <http:www.emater.tche.br/site/biblioteca/ptbr/htlm/ basedados/digital/agroeco030701.pdf>. Acesso em: 21 ago. 2008

20.MENDONÇA, S. R. Extensão rural e hegemonia norteamericana no Brasil. História Unisinos, v. 14, n. 2, p. 188-196, 2010 .

21.ROCHA, R. M. G. Construção do conceito da extensão universitária na América Latina. Brasília: Universidade de Brasília, 2001. 185 p.

22.PONS, M. A. História da agricultura. Caxias do Sul: Maneco Livraria \& Editora, 1998. 240 p.

23. CAPDEVILLE, G. O ensino superior agrícola no Brasil Viçosa: UFV, 1991. 184 p.

24.BRASIL. Ministério da Educação. Conselho Nacional de Educação. Resolução CNE/CES 1/2003. Diário Oficial da União, Brasília, 20 fev. de 2003. Sec. 1, p.15.

25. ABEAS. ASSOCIAÇÃO BRASILEIRA DE EDUCAÇÃO AGRICOLA SUPERIOR. Diretrizes Curriculares para os Cursos de Graduação. 2006. Disponível em: <http://www. abeas.com.br/wt/es_diretrizes.php> Acesso em: 15 ago. 2008.

26.DIAS, R. Fundamentos de sociologia geral. 2. ed. Campinas: Alínea, 2000. 